\title{
Studies of lead toxicity on inflammatory damage and innate immune functions in testicular macrophages of male Swiss albino mice
}

\author{
Shamim Ahmed S.K. Barbhuiya, Sumana Chakraborty, Mahuya Sengupta* \\ Department of Biotechnology, Assam University, Silchar, India; \\ *Corresponding Author: senguptamahuya35@gmail.com
}

Received 1 July 2013; revised 2 August 2013; accepted 11 August 2013

Copyright (C) 2013 Shamim Ahmed S.K. Barbhuiya et al. This is an open access article distributed under the Creative Commons Attribution License, which permits unrestricted use, distribution, and reproduction in any medium, provided the original work is properly cited.

\begin{abstract}
Immune infertility has gained impetus in recent years. Various scientific studies have been carried out on the toxic effects of lead on immune function; however, uncertainties still persist. The present study addresses the immunomodulatory effects of testicular macrophages caused due to lead exposure (in-vivo). In mice, lead has a primary effect on the testes, and acts at all levels of the reproductive as well as the testicular immune response. The study was undertaken to investigate the effects of lead acetate on immune system in Swiss albino mice and the underlying mechanism of pro-inflammatory cytokine action. The immunomodulatory effects of lead are complex and appear to involve multiple pathways, not all of which are fully understood. Testicular macrophage dysfunctions by lead was studied by calculating morphological alteration and associated cell functions of innate immunity followed by estimation of pro-inflammatory cytokine release (TNF- $\alpha$ ). The present work shows that lead is responsible for a significant morphological alteration, reducing cell function in testicular macrophages probably by increasing oxidative damage whereas increase in TNF- $\alpha$ release was also observed which increased inflammation. Results demonstrated that lead intoxication leads to increase in pro-inflammatory response. TNF- $\alpha$ is probably unable to bind with the surface receptor in testicular macrophages because of altered morphology which reduces cell function and ultimately causes reproductive dysfunction.
\end{abstract}

Keywords: Lead; Phagocytosis; Intracellular Killing; Scanning Electron Microscopy; Proinflammatory Cytokines

\section{INTRODUCTION}

Exposure of animals to lead and its derivatives in day-to-day life are unavoidable due to its wide applications and usage. Lead poisoning is one of the oldest and the most widely studied occupational and environmental hazards [1]. Although lead is one of the most useful metals, it is also considered as one of the most toxic metals. It was indicated that lead can cause neurological, hematological, gastrointestinal, respiratory, reproductive, circulatory and immunological pathologies [2], as well as reproductive dysfunctions [3]. The effect of lead on immunocompetent cell activity has been well studied [4]. Role of macrophages in heavy metal induced immunotoxicologic effect has been reported earlier [5]. In short it affects adversely almost all the systems of the body.

Reproductive consequences of lead exposure are widespread [2], affecting almost all aspects of reproduction [6, 7]. Lead induces decreased sperm count, motility and increased morphological abnormalities in animals $[8,9]$.

Lead is known to impede the male reproductive function; however the mechanisms through which the adverse effects are mediated are not clearly elucidated [10]. Lead intoxication results in the inhibition of testicular, epididymal and seminal vesicle function, altering the biochemical composition of this organ and affecting the normal development of germinal cells [11]. Growth effects of lead have been shown to be due to delay in the development of sex specific pituitary growth hormone secretion patterns [12]. In recent years study of immune-infertility has gained impetus. As the testes are immune-privileged organs, the effect of lead toxicity on testicular innate 
immunity remains a pertinent question. The present study attempts to evaluate the immunomodulatory properties of testicular macrophage functions, morphology, alteration of enzyme release, and pro-inflammatory response from murine testicular macrophages due to lead exposure in lead-intoxicated male albino mice.

\section{MATERIALS AND METHODOLOGY}

\subsection{Animals}

Adult male Swiss albino mice (average body wt $20 \mathrm{~g}$ ) were divided into two groups 1) Control 2) Lead treated groups. The second group was injected (i.p) with lead acetate solution $(10 \mathrm{mg} / \mathrm{kg}$ body $\mathrm{wt})$ and the control group with $0.9 \%$ isotonic saline daily for 15 days [5]. The animals were kept in plastic cages in the departmental animal house. Animal care and protocols were in accordance with and approved by the institutional animal ethics committee. These animals were kept in an environment with controlled temperature $\left(25^{\circ} \mathrm{C}\right)$, humidity (45\% - 50\%), and photoperiod (12:12-h light-dark cycle). All the animals were fed standard diet ad libitum and had free access to water. All experiments were conducted in triplicate.

\subsection{Analysis of Lead Bioaccumulation by Atomic Absorption Spectrophotometer}

The testes from treated and untreated group were allowed to dry at $120^{\circ} \mathrm{C}$ until reaching a constant weight, concentrated nitric acid and hydrogen peroxide $(1: 1 \mathrm{v} / \mathrm{v})$ (SD fine chemicals) was added. The digestion flasks were heated to $1300^{\circ} \mathrm{C}$ until all the materials were dissolved and diluted with double distilled water appropriately. The element lead was assayed using Shimadzu AA 6200 Atomic Absorption Spectrophotometer at the Sophisticated Analytical Instrument Facility (SAIF), NEHU, Shillong, Meghalaya. The results were expressed as $\mu 1 / \mathrm{ml}$.

\subsection{Isolation of Testicular Macrophages}

Testicular macrophages were isolated following a slightly modified procedure of Sikorski's method [13]. Macrophages from both control and lead exposed mice were used for assays.

\subsection{Preparation of Bacteria (Staphylococcus aureus MC524) for Intracellular Killing and Phagocytosis Assay}

To obtain bacteria in the mid-logarithmic phase $100 \mu \mathrm{l}$ of an overnight culture made in nutrient broth was added to $10 \mathrm{ml}$ of nutrient broth and incubated for $2-5 \mathrm{~h}$ at $37^{\circ} \mathrm{C}$ with orbital shaking. The bacteria were washed in $10 \mathrm{mM}$ sodium phosphate buffer $(\mathrm{pH} \mathrm{7.4)}$ and their con- centration was estimated by spectrophotometry at $\mathrm{A}_{620}$ on the basis of the relationship: $\mathrm{A}_{620} 0.2=5 \times 10^{7} / \mathrm{ml}[14]$.

\subsection{Morphological Alteration}

Testicular macrophages were taken in HBSS-BSA and fixed in $2.5 \%$ glutaraldehyde, centrifuged and the pellet resuspended in HBSS. Smears were drawn on glass slides and stained with Giemsa and observed under oil immersion microscope. Any cell deviating from spherical outline was scored as polarized and was expressed as a percentage of the total number of cells counted [15].

\subsection{Scanning Electron Microscopy}

The tissues were observed using a JSM-6360 (Jeol) SEM at the Sophisticated Analytical Instrument Facility (SAIF), North-Eastern Hill University (NEHU), Shillong, Meghalalya, India [16,17].

\subsection{Phagocytosis}

Testicular macrophage was taken on glass slides. Nonadherent cells were washed out with DPBS. Sheep erythrocytes (sRBC) is added to the glass slides with adhered macrophages, incubated and washed with DPBS. Slides were fixed in methanol and stained Giemsa and observed under oil immersion microscope. Phagocytosis index was calculated sRBC (average no. of SRBC per macrophage $\times 100)[18]$.

\subsection{Intracellular Killing}

Live bacteria incubated with testicular macrophage with DPBS-BSA. Non-ingested bacteria were removed by centrifugation. Cell containing ingested bacteria is resuspended in DPBS-BSA containing fetal calf serum. Samples are removed after different intervals and treated with gentamycin and plated in nutrient agar petriplate. Intra cellular killing was expressed as the percent decrease in the initial number of viable intracellular bacteria [19].

\subsection{Myeloperoxidase (MPO) Release Assay}

MPO release was estimated from macrophages following LPS stimulation in both control and treated mice using orthophenylenediamine (OPD) as substrate [20].

\subsection{Nitric Oxide (NO) Release Assay}

NO release was estimated after LPS stimulation in macrophages isolated from both control and treated mice with Griess reagent [21].

\subsection{Cytokine Assay}

Testicular cells were separated by density gradient centrifugation. Then testicular macrophages were obtained 
by adherence to plastic surface. A number of $1 \times 10^{5}$ viable cells in $0.2 \mathrm{ml}$ RPMI 1640 medium supplemented with 5\% FCS were distributed in microwells in flat 96 well microtitre plates and, after $24 \mathrm{~h}$ culture, supernatants were collected. Cytokine concentrations in culture supernatants were measured by sandwich ELISA estimating TNF- $\alpha$ using RayBio-Mouse TNF- $\alpha$ ELISA Kit. Biotinylated monoclonal secondary antibodies were used. The reaction was stopped with $3 \mathrm{M} \mathrm{H}_{2} \mathrm{SO}_{4}$ and the optical density of each well was measured in a 96-well plate reader at $450 \mathrm{~nm}$. All determinations were done in triplicate. Standard curves were generated by recombinant mouse cytokines. Lower density limits were $10 \mathrm{pg} / \mathrm{ml}$ $(\mathrm{TNF}-\alpha)$.

\subsection{Statistical Analysis}

The data were expressed as mean \pm standard deviation. Data were analyzed using Student's $t$-test (two-sample assuming unequal variances) for determining the significant changes over control values. The significance level was set at $P<0.05$ and $P<0.001$.

\section{RESULTS}

\subsection{Concentration of Lead (ppb) in Testes of Treated and Untreated Group of Mice}

After lead intoxication, the accumulation of lead was observed in testes of treated group whereas in control group traces of lead were not detected (Table 1).

\subsection{Effect of Lead on Morphological Alteration of Testicular Macrophages}

Morphological alteration was found to increase from $18.7 \% \pm 1.19 \%$ in control to $77.5 \% \pm 1.85 \%(P<0.001)$ in lead treated group (Figure 1).

\subsection{Effect of Lead on Morphology of Lead Intoxicated Testicular Macrophages by Scanning Electron Microscopy}

The scanning electron micrograph of testicular macrophages isolated from the respective groups showed that in lead intoxication, testicular macrophages showed less differentiation and so, were less efficient in dendritic morphology (Plate 1(b)) as compared to control groups (Plate 1(a)), showing presence of psuedopods.

Table 1. Concentration of lead accumulated in testes of treated and untreated group.

\begin{tabular}{cc}
\hline $\begin{array}{c}\text { Lead accumulation in untreated } \\
\text { group of mice }(\mathrm{ppb})\end{array}$ & $\begin{array}{c}\text { Lead accumulation in testes of lead } \\
\text { treated mice }(\mathrm{ppb})\end{array}$ \\
\hline Not detected & $1.256 \pm 0.008$ \\
\hline
\end{tabular}

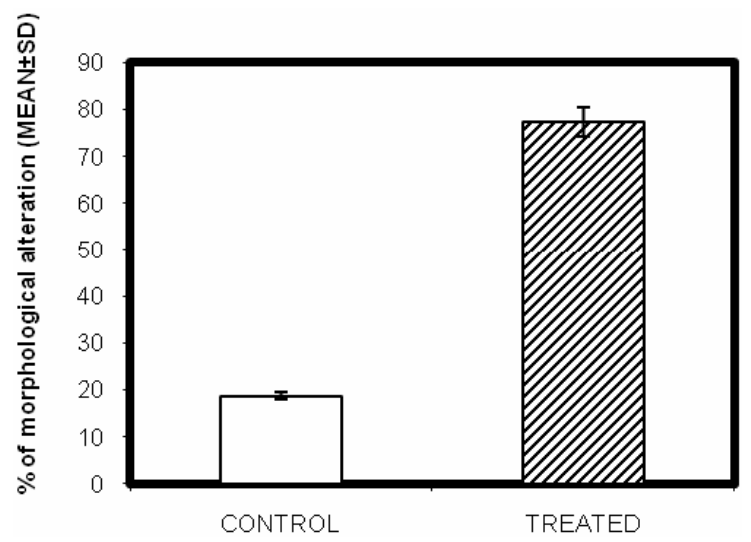

Figure 1. In-vivo study of effect of lead on the morphology of testicular macrophages in adult male Swiss albino mice. (Mean \pm S.D., $P<0.001$ ).

\subsection{Effect of Lead on Phagocytic Capacity of Lead Intoxicated Testicular Macrophages}

In order to determine whether there was any alteration in phagocytic capacity of testicular macrophages due to lead treatment, the phagocytosis of heat killed S. aureus by macrophages was assayed. Result shows that lead causes a marked decrease in the phagocytic index from $26333.33 \pm 1452.97$ in control to $6666.67 \pm 666.67$ after lead treatment (Figure 2; $P<0.001$ ).

\subsection{Effect of Lead on Killing Capacity of Testicular Macrophages}

This assay was performed to determine the killing capacity of intracellular $S$. aureus in cadmium treated and control group of mice. The result shows that lead treated mice are prone to infection and less effective in clearing invading pathogens as it was evident that testicular macrophages from lead exposed group were not able to kill the intracellular Staphylococcus aureus competently as shown in Figure 3; $(P<0.001)$.

\subsection{Effect of Lead on Myeloperoxidase Release of Testicular Macrophages Isolated from Lead Intoxicated Male Swiss Albino Mice}

Activation of macrophages with bacterial cell wall lipopolysaccharide (LPS) begins to express high levels of myeloperoxidase (MPO) enzyme. MPO decreases the free radical levels in our system. MPO release assay was performed to evaluate the effect of lead exposure on the release of this enzyme after LPS stimulation. Significant decrease in MPO released $(\mu \mathrm{M})$ was observed. MPO released from the control group with LPS stimulation, showed a value of $72.9 \pm 10.4 \mu \mathrm{M}$ and $15.9 \pm 2.23 \mu \mathrm{M}$ in the lead treated group (Figure 4; $P<0.05$ ). 


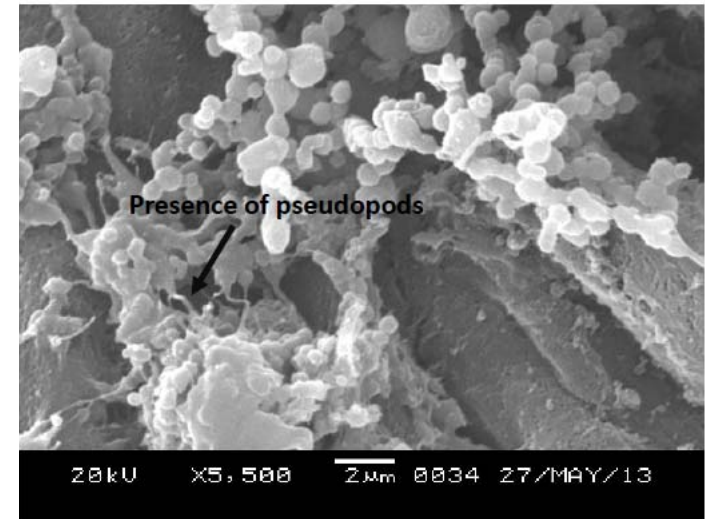

(a)

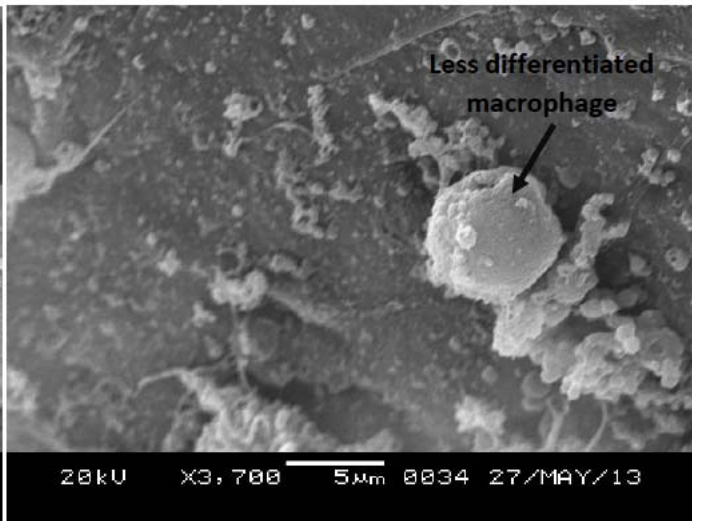

(b)

Plate 1. Effect of lead on macrophage differentiation. (a) The micrograph of normal macrophages at $\times 5500$ and the bar is $2 \mu \mathrm{m}$; (b) Micrograph of lead treated macrophages at $\times 3700$ and the bar is $5 \mu \mathrm{m}$.

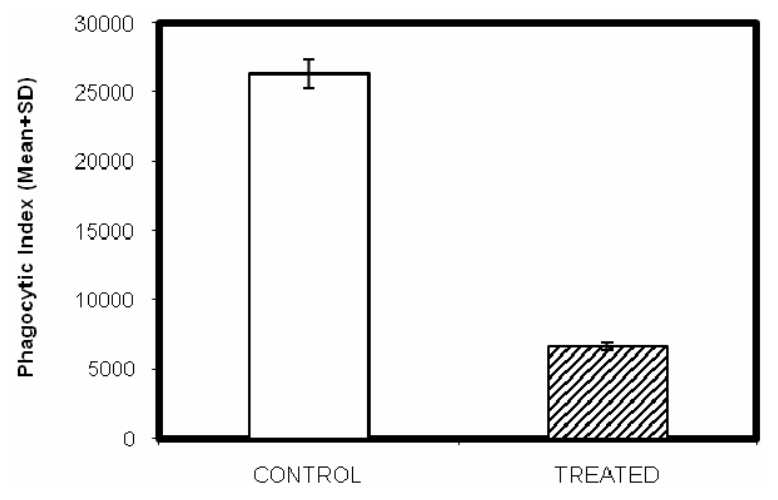

Figure 2. In-vivo study of effect of lead on phagocytic capacity of lead intoxicated testicular macrophages in adult male Swiss albino mice. (Mean \pm S.D., $P<0.001$ ).

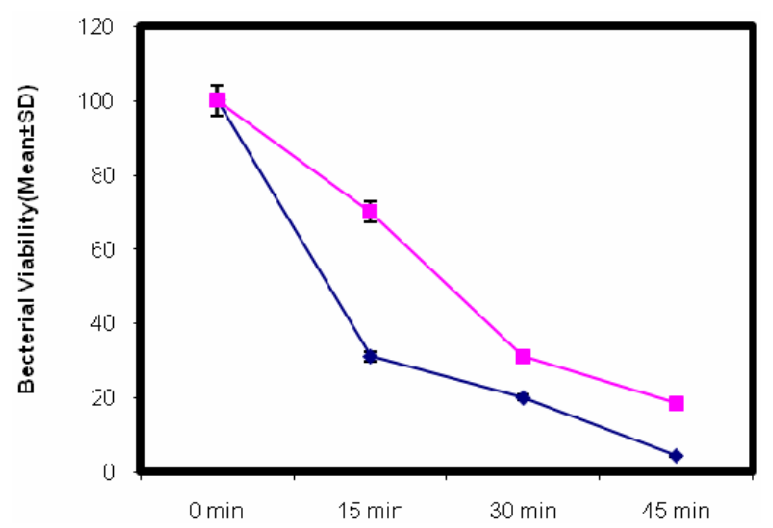

Figure 3. In-vivo study of effect of lead on killing capacity of testicular macrophages isolated from lead intoxicated adult male Swiss albino mice. (Mean \pm S.D., $P<0.01$ ).

\subsection{Effect of Lead on Nitric Oxide (NO) Release of Testicular Macrophages Isolated from Lead Intoxicated Male Swiss Albino Mice}

Macrophages, when activated with bacterial LPS, begin

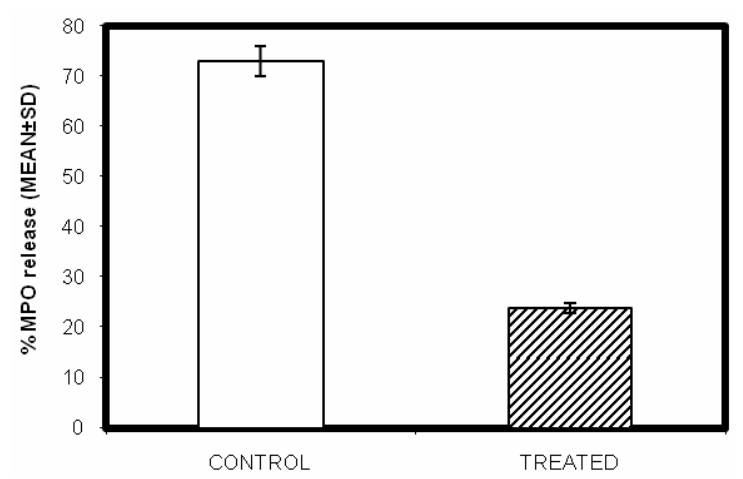

Figure 4. In-vivo study of effect of lead on myeloperoxidase enzyme release in testicular macrophages isolated from lead intoxicated adult male Swiss albino mice. (Mean \pm S.D., $P<0.05$ ).

to express high levels of nitric oxide synthase which oxidizes L-argininine to yield citrulline and nitric oxide (NO). NO itself has potent antimicrobial acitivity and it can also combine with superoxide anion to yield even more potent antimicrobial substances. The effect of lead on NO release seeks to demonstrate the immuno-modulatory effect of lead. Significant decrease in NO released $(\mu \mathrm{M})$ was observed in lead intoxicated group of mice. Result shows that lead causes a marked decrease in nitric oxide release (blue-control; pink-treated) from control $6.2 \pm 1.45 \mu \mathrm{M}$ to $3.6 \pm 1.9 \mu \mathrm{M}$ after lead treatment (Figure 5; $P<0.05$ ).

\subsection{Effect of Lead on Cytokines Pro-Inflammatory Release (TNF- $\alpha$ ) of Testicular Macrophages Isolated from Lead Intoxicated Male Swiss Albino Mice}

Intraperitoneal administration of lead in male Swiss albino mice led to an increase in the levels of pro-inflammatory cytokine; TNF- $\alpha$ from $195.33 \pm 0.88 \mathrm{Pg} / \mathrm{ml}$ to $252 \pm 1.73 \mathrm{Pg} / \mathrm{ml}$ (Figure 6; $P<0.05$ ). 


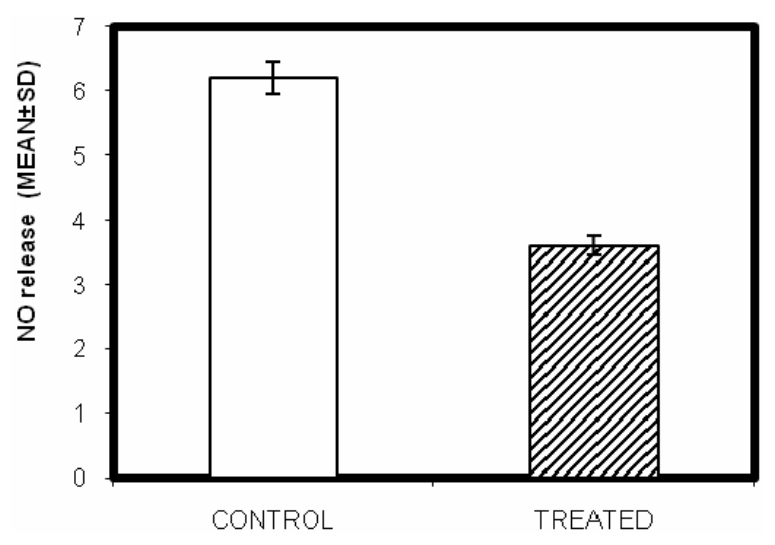

Figure 5. In-vivo study of effect of lead on nitric acid release in testicular macrophages isolated from lead intoxicated adult male Swiss albino mice. (Mean \pm S.D., $P<0.05$ ).

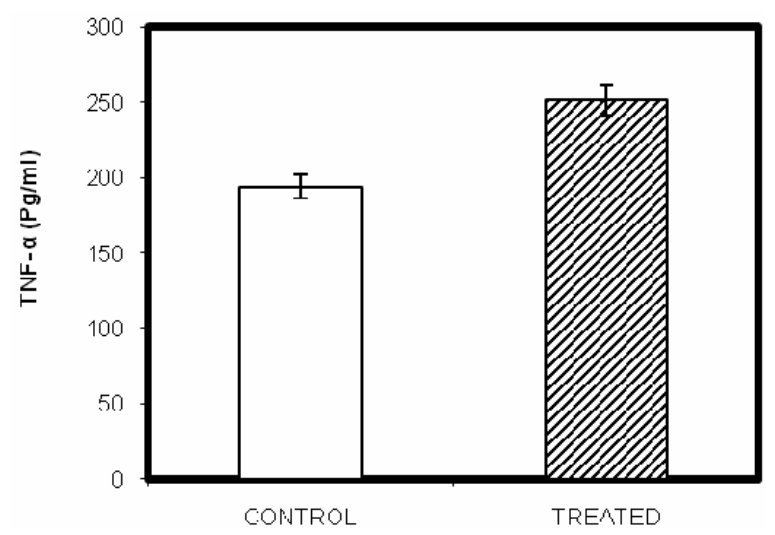

Figure 6. In-vivo study of effect of lead on pro-inflammatory (TNF- $\alpha$ ) cytokine release in testicular macrophages isolated from lead intoxicated adult male Swiss albino mice. (Mean \pm S.D., $P<0.05$ ).

\section{DISCUSSION}

Lead is a heavy metal that can be toxic when introduced into the human and animal bodies by ingestion on inhalation. It causes various destructive effects [22]. In human, increased level of lead causes many serious diseases and dysfunction of organs [23,24]. Although the testicular macrophages have been shown to be involved in endocrinological mechanisms within the testis, little information is available concerning their immunological competence.

To demonstrate the effects of lead exposure on the number of differentiated macrophages, the macrophage cells deviating from greater to lesser spherical outline were measured and counted under a microscope (Nikon). From this investigation, it was found that lead treatment increases the number of undifferentiated macrophages. Lead impairs differentiation features of murine testicular macrophages. This may lead to deleterious effects in lead treated patients. This alteration is possibly associated with a marked reorganization of actin cytoskeleton. For further clarity scanning electon microscopy were performed. Scanning electron micrograph of randomly selected area of lead intoxicated testes showed much smooth periphery which renders the differentiation of testicular macrophages and was deficient of pseudopods (dendritic extension) (Plate 1(b)) as compared to the control where distinct dendritic extension was visible (Plate 1(a)). It means that the number of differentiated macrophages was reduced in lead treated as compared to control group which confirms the alteration in surface morphology of the macrophages.

The purpose of this investigation was mainly to determine if these cells were capable of performing two major functions after intoxication of lead: phagocytosis and killing of bacteria by opsonization and receptor-mediated phagocytosis as well as secretion of enzymes and cytokines.

Testicular macrophages were found to be very effective in phagocytizing and killing a gram-positive pathogenic bacterium Staphylococcus aureus but it was found that the phagocytic index and the intracellular capacity of the testicular macrophages were reduced significantly due to lead exposure. This study indicates that lead exposed mice are more prone to infection since the testicular macrophages are unable to clear invading microorganism as evident from reduced phagocytic activity. Priming of testicular by $S$. aureus may activate the cells and is more active to phagocytose. Prolonged exposure to lead also destroys the ingestion capacity of testicular macrophages as it can be obtained from the intracellular killing assay.

Exposure of organisms to bacterial infection results in secretion of various lysosomal proteolytic enzymes, and immune-effectors from the macrophages viz myeloperoxidase (MPO) and nitric oxide (NO) respectively are able to kill tumor and bacterial cells. Immature macrophages have lesser lysosomal content and are thus, less capable of secreting such enzymes. In the present study it is observed that MPO and NO release in lead treated group are significantly lesser than the control group (invivo). The immune effector NO plays a major role not only as a cell signaling molecule level but also as a potent bactericidal agent.

Testicular expression of the proinflammatory cytokines TNF- $\alpha$ was considerably enhanced with lead exposure. The pro-inflammatory cytokine TNF- $\alpha$ in the testis is produced by round spermatids, pachytene spermatocytes, and testicular macrophages. The type 1 TNF receptor has been found on Sertoli and Leydig cells and numerous studies suggest a paracrine mode of action for TNF- $\alpha$ in the normal testis. Our study reveals that release of TNF- $\alpha$ decreases with the treatment lead treatment.

The current study demonstrates that exposure of male mice to lead acetate resulted in alteration in morphology 
of testicular macrophages; reduced phagocytosis index of testicular macrophages indicates that lead treated groups are more prone to infection, as they cannot phagocytose efficiently and so cannot clear out the invading microorganism. The results of this study strongly suggest that exposure to the heavy metal lead in the form of lead acetate had severe effects on testicular macrophages. Hence, it can be summarized that the toxic potential of lead is overtly manifested in the testes and this may bear particular significance in heavy metal induced infertility.

\section{REFERENCES}

[1] Florea, A.M. and Busselberg, D. (2006) Occurrence use and potential toxic effects of metals and metal compounds. Biometals, 19, 419-427.

http://dx.doi.org/10.1007/s10534-005-4451-x

[2] Patrick, L. (2006) Lead toxicity part II. The role of free radical damage and the use of antioxidants in the pathology and treatment of lead toxicity. Alternative Medicine Review, 11, 114-127.

[3] Marchlewicz, M., Proteasouicki, M., Rozewicka, L., Piasecka, M. and LaszeZynska, M. (1993) Effects of longterm exposure of lead on testis and epididymis in rats. Folia-Histochemica et Cytobiologica, 31, 55-62.

[4] Sengupta, M. and Bishayi, B. (2002) Effect of lead and arsenic on murine macrophage response. Drug and Chemical Toxicology, 25, 459-472.

http://dx.doi.org/10.1081/DCT-120014796

[5] Bishayi, B., Sengupta, M. and Ghosh, S. (2004) Lead induced modulation of splenic macrophage responses on humoral and cell mediated immunity. Acta Microbiologica et Immunologica Hungarica, 51, 31-45. http://dx.doi.org/10.1556/AMicr.51.2004.1-2.2

[6] Zheng, W., Aschmer, M. and Ghersi-Eger, J.M. (2003) Brain Barrier systems: A new frontier in metal neurotoxicological research. Toxicology and Applied Pharmacology, 192, 1-11.

http://dx.doi.org/10.1016/S0041-008X(03)00251-5

[7] Zheng, W., Aschner, M. and Ghersi-Egea, J.F. (2003) Brain barrier systems: A new frontier in metal neurotoxilologyical research. Toxicology and Applied Pharmacology, 192, 1-11.

http://dx.doi.org/10.1016/S0041-008X(03)00251-5

[8] Hsu, P.C., Hsu, C.C., Liu, M.Y., Chen, L.Y. and Guo, Y.L. (1998) Lead induced changes in spermatozoa function and metabolism. Journal of Toxicology and Environmental Health, Part A, 55, 45-64. http://dx.doi.org/10.1080/009841098158610

[9] Hsu, P.C., Liu, M.Y., Hsu, C.C., Chen, L.Y. and Guo, L. (1997) Lead exposure causes generation of reactive oxygen species and functional impairment in rat sperm. Toxicology, 122, 133-143. http://dx.doi.org/10.1016/S0300-483X(97)00090-5

[10] Thoreux-Manlay, A., Le Goascogne, C., Segretain, D., Jégou, B. and Pinon-Lataillade, G. (1995) Lead affects steroidogenesis in rat Leydig cells in vivo and in vitro.
Toxicology, 103, 53-62. http://dx.doi.org/10.1016/0300-483X(95)03107-Q

[11] Corpas, I., Castillo, M., Marquina, D. and Benito, M.J. (2002) Lead intoxication in gestational and lactation periods alters the development of male reproductive organs. Ecotoxicology and Environmental Safety, 53, 259-266. http://dx.doi.org/10.1006/eesa.2002.2230

[12] Ronis, M.J.J., Badger, T.M., Shema, S., Roberson, P.K. and Shaikh, F. (1996) Reproductive toxicity and growth effects in rats exposed to lead at different periods during development. Toxicology and Applied Pharmacology, 136, 361-371. http://dx.doi.org/10.1006/taap.1996.0044

[13] Sikorski, E.E., Burns, L.A., Stern, M.L., Luster, M.I. and Munson, A.E. (1991) Splenic cell targets in gallium arsenide-induced suppression of the primary antibody response. Toxicology and Applied Pharmacology, 110, 129142. http://dx.doi.org/10.1016/0041-008X(91)90296-Q

[14] Yao, L., Berman, J.W., Factor, S.M. and Lowy, F.D. (1997) Correlation of histopathologic and bacteriologic changes with cytokine expression in experimental murine model of bacteremic Staphylococcus aureus infection. Infection and Immunity, 65, 3889-3895.

[15] Qu, J., Condliffe, M.A., Lawson, M., Plevin, R.J. and Chlivers, E. (1997) Lack of effect of recombinant platelet derived growth factor on human neutrophil function. The Journal of Immunology, 159, 2952-2959.

[16] Dey, S. (1993) A new rapid air drying technique for scanning electron microscopy using tetramethylsilane. Application to mammalian tissue. Cytobiology, 73, 17-23.

[17] Dey, S., Basu Baul, T.S., Roy, B. and Dey, D. (1989) A new rapid method of air-drying for scanning electron microscopy using tetramethylsilane. Journal of Microscopy, 156, 2259-2261.

http://dx.doi.org/10.1111/j.1365-2818.1989.tb02925.x

[18] Czuprynski, C.J., Henson, P.M. and Campbell, P.A. (1984) Killing of Listeria monocytogenes by inflammatory neutrophils and mononuclear phagocytes from immune and non immune mice. Journal of Leukocyte Biology, 35, 193-208.

[19] Leigh, P.C.J., Van Furth, R. and Zwet, T.L. (1986) In vitro determination of phagocytosis and intracellular killing by polymorphonuclear neutrophils and mononuclear phagocytes. In: Weir, D.M., Ed., Handbook of Experimental Immunology, 4th Edition, Blackwell Scientific Publications, 46, 1-46.

[20] Bos, A.R., Weaver, R. and Roos, D. (1990) Characterization and qualification of the peroxidase in human neutrophils. Biochimica et Biophysica Acta, 525, 4133-4141.

[21] Sasaki, S., Miura, T., Nishikawa, S., Yamada, K., Hirasue, M. and Nakane, A. (1998) Protective role of nitric oxide in S. aureus infection in mice. Infection and Immunity, 66, 1017-1018.

[22] Neathery, M. and Miller, W. (1975) Metabolism and toxicity of cadmium, mercury, and lead in animals. Department of Animal and Dairy Science, 58, 1767-1781. http://dx.doi.org/10.3168/jds.S0022-0302(75)84785-0

[23] Gennart, J.P., Bernard, A. and Lanwerys, R. (1992) Assessment of thyroid, testes, kidney and autonomic nerv- 
ous system function in lead exposed workers. International Archives of Occupational and Environmental Health, 64, 49-57. http://dx.doi.org/10.1007/BF00625951

[24] McGregor, A.J. and Mason, M.J. (1990) Chronic occupa- tional lead exposure and testicular endocrine function. Human \& Experimental Toxicology, 9, 371-376. http://dx.doi.org/10.1177/096032719000900602 